\title{
Peran Kepemimpinan Kepala Sekolah dalam Meningkatkan Mutu Pendidikan melalui Manajemen Berbasis Sekolah
}

\author{
Emilia Kurniawati ${ }^{\varpi 1}$, Yasir Arafat ${ }^{2}$, Yenny Puspita ${ }^{3}$ \\ (1) Sekolah Dasar Negeri 14 Betung
}

$(2,3)$ Universitas PGRI Palembang

$\triangle$ Corresponding author

[emiliakurniawati05@gmail.com]

\begin{abstract}
Abstrak
Penelitian ini mendiskripsikan tentang peranan kepemimpinan dalam meningkatkan mutu pendidikan melalui Manajemen Berbasis Sekolah yang diterapkan di SD Negeri 14 Betung dengan rumusan masalah penelitiannya. Penelitian ini menggunakan pendekatan penelitian kualitatif dengan jenis fenomenologic naturalistic. Data penelitian diperoleh dengan teknik pengamatan terlibat, wawancara mendalam dan dokumentasi. informan dalam penelitian ini, Kepala Sekolah dan guru. Hasil penelitian menyimpulkan bahwa Kepala Sekolah telah melaksanakan peran utamanya sebagai pemimpin dan manajer dengan baik, di samping peran yang lainnya adalah seorang wirausahawan yang tangguh dalam upaya meningkatkan mutu pendidikan. Strategi yang dilakukan untuk meningkatkan mutu pendidikan di SD Negeri 14 Betung melalui Manajemen Berbasis Sekolah (MBS) cukup bagus, hal ini dapat dilihat dari kinerja kepala sekolah, guru, karyawan,dalam berkolaborasi dan menjalin komunikasi dalam melaksanakan setiap kegiatan yang menjadi tugas dan tanggung jawabnya demi tercapainya tujuan pendidikan yang diharapkan.
\end{abstract}

Kata Kunci: Peran Kepemimpinan; Mutu Pendidikan; Manajemen Berbasis Sekolah.

\begin{abstract}
This study described the role leadership in improving education quality thourgh the schoolbasedmanagement applied in SD Negeri 14 Betung Banyuasin. This study used the qualitative approach with phenomenological naturalistic type. Data was collected through observation, in-depth interview, and documentation. The key informant was the headmaster and teachers. The results of the study concluded that the principal had carried out his main role as a leader and manager well, in addition to his other roles; he was a tough entrepreneur in an effort to improve the quality of education. The strategy carried out to improve the quality of education at SD Negeri 14 Betung through School Based Management is quite good, this can be seen from the performance of school principals, teachers, employees, in collaborating and establishing communication in carrying out every activity that is their duty and responsibility. in order to achieve the expected educational goals.
\end{abstract}

Keyword: Role of Leadership; Education Quality; School- Based Management.

\section{PENDAHULUAN}

bergeraknya semua kegiatan di sekolah yang melalui kemampuan konseptual yang dimilikinya ia mengembangkan sekolah. Melalui kemampuan sosial, ia menggerakkan, mengayomi, dan memberi rasa aman dan nyaman pada orang -orang di bawah kepemimpinannya serta orang-orang di luar sekolah yang berkepentingan. Melalui kemampuan teknis, ia akan mendeskresikan cara melakukan pekerjaan dengan mitra kerjanya. Mengkomunikasikan secara efektif tentang rencana, implementasi, dan hasil kerja. Mengupayakan terbentuknya kerja sama kelompok dan pemimpin harus memiliki komitmen yaitu niat yang kuat untuk melaksanakan tugas dan kewajiban yang diembannya (Mulyasa, 2004; Abdullah, 2020; Soleh dkk, 2019; Fitria dan Suminah, 2020).

Peningkatan kualitas sekolah merupakan hal yang perlu direncanakan dan dilaksanakan, sesuai dengan sasaran kerja dan target yang akan dicapai berdasarkan visi misi, dan tujuan yang ditetapkan dalam jangka waktu yang ditentukan. Kondisi tersebut perlu adanya berbagai upaya perbaikan untuk meningkatkan mutu pendidikan dengan "berjuang melawan keadaan" sampai menjadi terbelenggu. Sesungguhnya sangat ingin merubah keadaan untuk menjadi lebih baik, namun tidak mau mengubah dirinya lebih baik (Mukartik dkk, 2020; Zulaiha dkk, 2020; Darmiati dkk, 2020; Hamzah dkk, 2020). 
Sebagai Kepala Sekolah tentunya memilki strategi tersendiri dalam hal menjaga eksistensi SDN 14 Betung, yang sudah pasti juga dibantu oleh beberapa pihak yaitu seluruh satuan pendidikan sekolah tersebut tanpa dukungan dan kerjasama dari seluruh tenaga pendidik dan tenaga kependidikan tentunya kepala sekolah juga tidak akan mampu menjalakan tugasnya. Sebagai kepala sekolah tentu juga memilki hambatan tersendiri dalam hal tersebut baik itu datangnya dari faktor intern dan juga faktor ekstern .Melihat begitu penting suatu lembaga pendidikan dalam mengatur diri secara mandiri dengan menggunakan manajemen berbasis sekolah, maka SDN 14 Betung memerlukan Manajemen Berbasis Sekolah dalam meningkatkan mutu dan meningkatkan kualitas pendidik sehingga mendapatkan akreditasi sekolah yang sangat memuaskan sekolah tersebut dan melihat begitu besar peran kepala sekolah dalam menyelenggarakan pendidikan (Zamroni, 2000; Listiningrum dkk, 2020; Ivanova dkk, 2020; Komalasari dkk, 2020; Nugraha, 2019).

Kepala sekolah berusaha memperbaiki Manajemen Berbasis Sekolah yang sudah dijalankan selama ini di SDN 14 Betung. Berdasarkan hasil observasi awal yang peneliti lakukan bahwa pelaksanaan Manajemen Berbasis Sekolah di SDN 14 Betung sudah berjalan. SDN 14 Betung mampu menjalankan Manajemen Berbasis Sekolah walaupun bukan sekolah yang bukan SBI (Sekolah Berstandar Internasional) (Rohma dkk, 2020; Risdianto dkk, 2020; Septiani dan Cahyono, 2019). Namun berdasarkan wawancara dengan kepala sekolah SDN 14 Betung, bahwa dalam hal pelaksanaan Manajemen Berbasis Sekolah tentunya masih mengalami beberapa kendala baik itu secara eksternal maupun internal. Jadi, berdasarkan permasalahan-permasalahan tersebut peneliti tertarik untuk melakukan penelitian tentang "Peranan Kepemimpinan Dalam Meningkatkan Mutu Pendidikan Melalui Manajemen Berbasis Sekolah".

\section{METODE PENELITIAN}

Jenis penelitian ini adalah penelitian kualitatif yang akan digunakan untuk meneliti dan mendeskripsikan tentang Peran Kepala Sekolah dalam pelaksanaan Manajemen Berbasis Sekolah di SDN 14 Betung.Jadi jenis penelitian ini berdasarkan tempat penelitiannya adalah penelitian lapangan,dimana peneliti akan terjun langsung kelapangan untuk melihat secara langsung yang menjadi subjek penelitian. Penelitian kualitatif terdapat tiga teknik pengumpulan data, yaitu wawancara, dokumentasi, observasi. Dalam penelitian ini, teknik pengumpulan data primer menggunakan metode wawancara terstruktur, yang dilakukan dengan cara membuat pedoman wawancara dengan beberapa butirpertanyaan dalam kegiatan pelaksanan MBS di SDN 14 Betung antara lain yaitu Kepala Sekolah dan guru kelas.

Tekhnik pengumpulan data wawancara Mendalam: Penelitian ini peneliti melakukan wawancara mendalam untuk mengetahui secara mendalam mengenai pelaksanaan MBS di sekolah tersebut. Peneliti melakukan wawancara secara terbuka kepada kepala sekolah dan Guru wali kelas dengan mengunakan rekaman suara di hanphone. Adapun langakah langakah yang peneliti lakukan yaitu 1) membuat instrumen penelitian; 2) menentukan subjek penelitian; 3) menyiapkan beberpa pertanyan yang akan menjadi gambaran umum mnegenai pembentukan MBS; 4) membuka alur wawancara; 5) melangsungkan wawancara; 6) mengkonfirmasi ikshtisar dari hasil wawancara; dan mengakhirinya; 7) menulis hasil wawancara; dan 8) mengidentifiksi tindak lanjut hasil wawancara. Observasi: peneliti berpasrtispasi langsung dalam kegiatan yang dilakukan sekolah sesuai dengan permasalahan yang ingin diteliti oleh peneliti dan peneliti mencoba melhat secara langsung bagaimana proses pelaksanaan MBS dan siapa saja yang terlibat didalamnya. Dokumentasi Untuk menguatkan penelitian yang dilakukan oleh peneliti, maka peneliti juga memiliki bebarapa dokumen yang terdapat di SDN 14 Betung. Adapun dokumen yang dimaksud disni adalah berupa foto-foto kegiatan sekolah, arsip sekolah sarana dan prasarana, transkip wawancara serta dokumentasi.

\section{HASIL DAN PEMBAHASAN}

Sekolah Dasar Negeri 14 Betung merupakan salah satu sekolah negeri yang diminati oleh masyarakat untuk menyekolahkan putra putrinya. Hal ini dibuktikan bahwa jumlah pendaftar selalu melampaui target. Pada tahun pelajaran 2018/2019 jumlah pendaftar 103 dan yang diterima 56 peserta didik yaitu 2 rombel. Dikarenakan di samping lokasinya yang sangat strategis, salah satunya telah terjadi perubahan dan peningkatan mutu di sekolah tersebut, baik perubahan dalam prestasi dalam bidang akademik dan non akademik ataupun dalam bentuk fisik maupun non fisik. Prestasi yang diperoleh sekolah tersebut tidak lepas dari peranan kepemimpinan dan manajemen serta team yang kuat (Anees, 2008).

Kepemimpinan merupakan suatu hal yang menarik untuk dibahas, karena kepemimpinan menjadi salah satu faktor yang sangat menentukan keberhasilan suatu organisas di samping manajemen. Kepemimpinan merupakan bagian terpenting dalam suatu manajemen, di samping fungsi-fungsi yang lainnya. Meskipun masih banyak faktor lain yang turut mempengaruhi dalam keberhasilan suatu organisasi. Kepemimpinan menempati posisi yang sangat penting bagi jalannya sistem yang ada dalam organisasi, di samping faktor-faktor lain yang turut berpengaruh terhadap tercapainya suatu tujuan seperti: struktur organisasi yang akurat, pendanaan dan tenaga profesional yang cukup memadai. Peningkatan mutu pendidikan tidak akan terjadi tanpa adanya kepemimpinan yang profesional dan manajemen yang baik selain 
peran lain yang dilakukan seorang pemimpin kepala sekolah secara keseluruhan (Asmani, 2012; Amalia, 2019; Apriani, 2020).

Perubahan dan peningkatan mutu sekolah tersebut di antaranya banyak dipengaruhi oleh peran kepala sekolah yang kuat dalam memimpin dan pengelolaannya. Hal ini disampaikan Tuti Eka Warni, S. Pd kepada penulis Kepala sekolah yang kuat ini ditunjukkan dengan ketegasannya dalam mengambil sikap dan mengambil keputusan, konsisten, dan berkomitmen dalam melaksanakan program-programnya yang telah disepakati bersama dengan tetap memperhatikan kondisi yang beragam.

Inisiatif untuk mengadakan perubahan dengan melakukan upaya perbaikan mutu secara berkesinambungan yang dimulai dari pihak pimpinan dan warga sekolah serta tuntutan dari masyarakat. Berikut ini penjelasan Abdul Hamid, S.Pd (kepala sekolah) kepada peneliti banyak faktor yang berpengaruh terhadap keberhasilan peningkatan mutu selain faktor kepemimpinan dan manajemen antara lain : faktor tim yang kuat, adanya partisipasi dan faktor deployment dengan mengadakan promosi yang melibatkan seluruh warga sekolah dengan masyarakat, semua warga sekolah ada kemauan untuk berubah, guru, karyawan tahu, mau, mampu apa yang menjadi tanggungjawabnya dan yang harus dikerjakan serta melakukan evaluasi juga perubahan secara berkelanjutan.

Masing-masing faktor yang mendukung keberhasilan dalam peningkatan mutu sekolah tersebut berfungsi saling melengkapi satu sama lainnya. Dalam hal ini, Dias menyampaikan semua faktor saling melengkapi, semua warga sekolah, masyarakat saling berkolaborasi dalam melaksanakan tugasnya, bisa menyesuaikan diri dengan situasi dan kondisi yang selalu berubah serta beragam, menjalin komunikasi yang baik dengan pihak-pihak terkait.

Adanya peningkatan mutu pendidikan di SD Negeri 14 Betung, tidak terlepas dari peran kepala sekolah di antaranya sebagai figur pemimpin yang mampu menggerakkan, mengarahkan dan memotivasi adanya perubahan tersebut. Di samping peran kepala sekolah sebagai leadership yang merupakan bagian terpenting dalam manajemen sekolah, ada peranan kepala sekolah yang lain selain sebagai pemimpin dalam rangka meningkatkan mutu pendidikannya. Berdasarkan Permendikbud No. 15 Tahun 2018 Psl 9 ayat 1 dan 4 sebenarnya tugas utama seorang kepala sekolah adalah sebagai pemimpin (leader) dan pengelola (manajer) serta beban kerja kepala sekolah sepenuhnya untuk melaksanakan tugas manajerial, pengembangan kewirausahaan, dan supervisi kepada guru dan tenaga kependidikan. Kepala sekolah dapat melaksanakan tugas pembelajaran atau pembimbingan apabila terdapat guru yang tidak melaksanakan tugas pembelajaran atau pembimbingan karena alasan tertentu yang bersifat sementaran atau tetap atau belum tersedia guru yang mengampu pada mata pelajaran atau kelas tertentu namun kepala sekolah menjelaskan bahwa peran kepemimpinan kepala sekolah tersebut secara rinci sebagai : Educator, Manajer, Administrator, Supervisor, Leader, Inovator, Motivator, dan menjadi Figur serta Mediator (EMASLIM + FMPW).

\section{SIMPULAN}

Kepala Sekolah telah melaksanakan peran utamanya sebagai pemimpin dan manajer dengan baik, di samping peran yang lainnya adalah seorang wirausahawan yang tangguh dalam upaya meningkatkan mutu pendidikan. Sebagai seorang wirausahawan yang tangguh, pekerja keras dan cerdas kreatif, inovatif, komitmen dan berusaha memberikan teladan bagi warga sekolahnya Kepala sekolah SDN 14 Betung telah melaksanakan fungsi sebagai pemimpin dan sebagai hasil dari penelitian adalah meningkatnya prestasi siswa; 2) Strategi yang dilakukan untuk meningkatkan mutu pendidikan di SD Negeri 14 Betung melalui Manajemen Berbasis Sekolah (MBS) cukup bagus, hal ini dapat dilihat dari kinerja kepala sekolah, guru, karyawan, dalam berkolaborasi dan menjalin komunikasi dalam melaksanakan setiap kegiatan yang menjadi tugas dan tanggung jawabnya demi tercapainya tujuan pendidikan yang diharapkan. Kinerja tersebut dilakukan dengan cara menyusun strategi peningkatan mutu pendidikan di sekolah tersebut dengan melakukan : analisis lingkungan, menganalisis kesenjangan kondisi sekolah saat ini dan kondisi yang diharapkan pada jangka menengah dan pendek mengatasi kesenjangan secara bertahab, melaksanakan program dan, memonitoring mengevaluasi program-program tersebut secara berkesinambungan untuk aksi lebih lanjut. Kepala Sekolah SDN 14 Betung melakukan strategi dalam pelaksanaan MBS yaitu dengan cara pembinaan disiplin dan menjadikan dirinya sebagai contoh disiplin kepada seluruh masyarakat sekolah yaitu dengan cara selalu hadir tepat waktu, meyelesaikan semua tugasnya, dan juga selalu hadir lebih cepat diruang rapat dibandingkan dengan guru lainnya; Kepala Sekolah SDN 14 Betung masih banyaknya mengalami hambatan dalam hal kurangnya pengetahuan para staf dan guru mengenai MBS serta adanya pemikiran yang kohesif. Tetapi kepala sekolah selalu berusahauntuk hal pemikiran kohesif itu bersifat positif.

\section{UCAPAN TERIMA KASIH}

Terima kasih penulis ucapkan kepada kepadla sekolah dan guru Sekolah Dasar Negeri 14 Betung dan semua pihak yang telah membantu selesainya penelitian ini. 


\section{DAFTAR PUSTAKA}

Abdullah, A. (2020). Relationship the Work Culture and Training Programs Within Performance. International Journal of Progressive Sciences and Technologies (IJPSAT), 20(1).

Amalia, D. (2019). Promoting Just Culture For Enhancing Safety Culture In Aerodrome Airside Operation. International Journal of Scientific \& Technology Research 8 (10)

Anees, B. Q., \& Hambali, A. (2008). Pendidikan Karakter Berbasis al- Qur'an. Bandung: Simbiosa Rekatama Media.

Apriani, N., Fatonah, F., \& Oka, I. A. M. (2020). Rancangan Sistem Pengolahan Sertifikat Berbasis Website Sebagai Upaya Untuk Peningkatan Evaluasi Kompetensi Safety Personil Di Lingkungan PT Angkasa Pura II (Persero). Langit Biru: Jurnal IImiah Aviasi, 17-28.

Asmani, J. M. (2012). Tips Menjadi Kepala Sekolah Profesional. Jogjakarta: Diva Press.

Darmiati, D., Kristiawan, M., \& Rohana, R. (2020). The Influence of School Leadership and Work Motivation toward Teacher's Discipline. Journal of Social Work and Science Education, 1(1), 32-44.

Fitria, H., \& Suminah, S. (2020). Role of Teachers in Digital Instructional Era. Journal of Social Work and Science Education, 1(1), 70-77.

Hamzah, S., Yussof, M. H. B., \& Enriquez, A. A. (2020). Togetherness in the Diversity of the Pancasila Ideology Frame. Journal of Social Work and Science Education, 1(1), 8-12.

Ivanova, T., Gubanova, N., Shakirova, I., \& Masitoh, F. (2020). Educational technology as one of the terms for enhancing public speaking skills. Universidad y Sociedad, 12(2), 154-159.

Komalasari, K., Arafat, Y., \& Mulyadi, M. (2020). Principal's Management Competencies in Improving the Quality of Education. Journal of Social Work and Science Education, 1(2), 181-193.

Listiningrum, H. D., Wisetsri, W., \& Boussanlegue, T. C. H. A. B. L. E. (2020). Principal's Entrepreneurship Competence in Improving Teacher's Entrepreneurial Skill in High Schools. Journal of Social Work and Science Education, 1(1), 87-95.

Mulyasa, (2004). Menjadi Kepala Sekolah Profesionalisme. Bandung: Remaja Rosdakarya.

Murkatik, K., Harapan, E., \& Wardiah, D. (2020). The Influence of Professional and Pedagogic Competence on Teacher's Performance. Journal of Social Work and Science Education, 1(1), 58-69.

Nugraha, W. (2019) Safety Documentation: A Communication Approach For Safety Management System In Aerodrome Operator. International Journal of Scientific \& Technology Research 8 (11), 1705-1711

Risdianto, E., Fitria, J., Johan, H., \& Macariola, J. S. (2020). Teacher's Perception of Thermodynamic Law Module Developed in Training through Student's Critical Thinking Skills. Journal of Social Work and Science Education, 1(1), 78-86.

Rohma, S., Harapan, E., \& Wardiah, D. (2020). The Influence of School-Based Management and Teacher's Professionalism toward Teacher's Performance. Journal of Social Work and Science Education, 1(1), 13-23.

Septiani, V., \& Cahyono, D. (2019). Education and Training Strategy in Palembang Aviation College. International Journal of Recent Technology and Engineering, 8 (3)

Soleh, A. M., Tobari., Kesumawati, N. (2019). Development of The Practical Manual as A Learning Media for Simulator Aircraft Rescue and Fire Fighting. International Journal of Scientific \& Technology Research 8(10).

Zulaiha, D., Lian, B., \& Mulyadi, M. (2020). The Effect of Principal's Competence and Community Participation on the Quality of Educational Services. Journal of Social Work and Science Education, 1(1), 45-57. 